\title{
Prenatal Diagnosis of Collagen Disorders by Direct Biochemical Analysis of Chorionic Villus Biopsies ${ }^{1}$
}

\author{
MICHAEL RAGHUNATH, BEAT STEINMANN, CELIA DELOZIER-BLANCHET, \\ PHILIPPE EXTERMANN, AND ANDREA SUPERTI-FURGA \\ Department of Pediatrics, Division of Metabolism, University of Zürich, Zürich, Switzerland \\ [M.R., B.S., A.S.-F.], and Division of Medical Genetics [C.D.-B.] and Department of \\ Gynecology and Obstetrics [P.E.], University of Geneva, Geneva, Switzerland
}

ABSTRACT

We have developed a method for early prenatal diagnosis of molecular disorders of collagens I and III. The method takes advantage of the fact that isolated chorionic villi contain significant amounts of collagens in their extracellular matrix (stroma) and that they synthesize collagens in vitro. After metabolic labeling of chorion villus biopsies in toto with radioactive amino acids, collagens are extracted and analyzed by SDS-PAGE. Direct staining of the gel shows collagens synthesized in vivo, whereas autoradiofluorography identifies collagens synthesized during incubation in vitro. Unlike collagens synthesized by cultured amniotic fluid cells, collagens extracted from chorionic villi are not overmodified and thus allow better identification of molecular defects. Results are available within 3 to $5 \mathrm{~d}$ after biopsy. Using this method, we have correctly excluded Ehlers-Danlos syndrome type IV in two pregnancies, Ehlers-Danlos syndrome type VII in one pregnancy, and lethal osteogenesis imperfecta in four pregnancies. In addition, we correctly predicted a healthy fetus and an embryo

OI and EDS types VII and IV are heritable connective tissue disorders associated with molecular defects of collagen I (OI and EDS VII) and collagen III (EDS IV) $(1,2)$. Collagen I is a heterotrimer composed of two proa1(I)chains and one proa2(I)-chain that form a triple helix. The genes coding for these pro $\alpha$-chains, COL1A1 and COL1A2, are located on chromosomes 17 and 7, respectively (3). In contrast, collagen III is a homotrimer composed of three pro $\alpha$ (III)-chains coded for by $C O L 3 A 1$ on chromosome 2 (3).

Received February 1, 1994; accepted May 5, 1994.

Correspondence: Beat Steinmann, M.D., Division of Metabolism, Department of Pediatrics, University of Zürich, Steinwiesstr. 75, CH-8032 Zürich, Switzerland.

Supported by the Swiss National Science Foundation (Grants 32-27884.89/1+2 and 32-36387.92).

${ }^{1}$ Presented in part in abstract form (Raghunath M, Steinmann B, DeLozierBlanchet C, Extermann P, Superti-Furga A: Direct biochemical analysis of collagens in chorion villus biopsies: prenatal diagnosis of recurrent lethal osteogenesis imperfecta caused by parental mosaicism for a COL1A1 mutation. Eur J Pediatr 153:216, 1994). affected with lethal osteogenesis imperfecta in consecutive pregnancies from a couple in which the asymptomatic mother was a somatic mosaic for a COLIA1 G-to-A transition (Gly355Asp). Direct collagen analysis of chorion villus biopsies labeled in toto is rapid and reliable and may become the method of choice for the prenatal diagnosis of selected collagen disorders. (Pediatr Res 36: 441-448, 1994)

CV, chorionic villus

Abbreviations

CVS, chorionic villus sample

CVC, chorionic villus cell

CVOC, chorionic villus organ culture

AFC, amniotic fluid cell

EDS, Ehlers-Danlos syndrome

OI, osteogenesis imperfecta

MEM, minimum essential medium

PCR, polymerase chain reaction

SSCP, single-strand conformational polymorphism

Biochemical analysis of collagens synthesized by cultured skin fibroblasts is currently the standard method for diagnostic confirmation of OI, EDS IV, and EDS VII. Cultured fibroblasts synthesize and secrete both collagens I and III, and alterations in the structure and/or the quantity of these collagens can be demonstrated in most (although not all) patients affected with OI, EDS IV, and EDS VII.

EDS IV, EDS VII, and severe forms of OI are crippling or even life-threatening conditions. For prospective parents affected by these conditions, the risk of having an affected child is $50 \%$, whereas for parents of a sporadic patient with lethal OI, the recurrence risk is 5 to $8 \%$ (4, 5 ). Because prenatal diagnosis is often requested by couples at risk, efforts have been made to develop methods for the early identification of affected fetuses by means of ultrasonography, biochemistry, and DNA analyses. Transabdominal ultrasound examination is effective in identifying fetuses with perinatally lethal OI (OI type II) 
by 14-17 wk gestation and most fetuses with progressively deforming OI (OI type III) by 20 wk gestation. In the absence of fractures or deformities, however, less severe forms of OI (OI types I and IV) cannot be reliably identified by ultrasonography $(1,6)$. There is no experience concerning prenatal diagnosis of EDS IV or EDS VII by ultrasound analysis, although congenital hip dislocation, an obligate feature of EDS VII, might be detectable in the third trimester (2). Genetic linkage analysis using markers linked to COL1A1 and COL1A2 has been used for the prenatal diagnosis of OI. However, this approach requires knowledge about the linkage phase and thus requires a sufficiently large and informative family. Although direct identification of the genomic mutation is most straightforward, availability of this approach is presently restricted because it requires prior elucidation of the mutation in the index case. Biochemical analysis of the collagens synthesized by cultured AFC or CVC from biopsies has been attempted with the same prerequisite, i.e. the definition of a biochemical defect in the index case. Biochemical anomalies can be identified by SDS-PAGE either as additional bands corresponding to abnormal $\alpha 1(\mathrm{I})$-, $\alpha 2(\mathrm{I})$-, or $\alpha 1$ (III)-chains (such as those induced by exonskipping mutations, deletions or insertions, or cysteine substitutions in $\alpha 1(\mathrm{I})$ - or $\alpha 1$ (III)-chains) or as bands showing retarded migration because of posttranslational overmodification of $\alpha(\mathrm{I})-, \alpha 2(\mathrm{I})-$, or $\alpha 1$ (III)-chains (1) due to delayed helix formation (7).

Shapiro et al. (8) established AFC cultures at wk 21 immediately before termination of a pregnancy with radiographically diagnosed OI type II. Although they reported biochemical differences from control AFC, it has since become clear that AFC are of limited use for the prenatal diagnosis of $\mathrm{OI}$ because they synthesize exclusively overmodified proa1(I) homotrimers, a variant of procollagen I composed of three proa1(I)-chains $(9,10)$ (see below).

Recently, CVC obtained from the placenta of a vaginally delivered 32-wk fetus were used for biochemical collagen analysis after the positive ultrasound diagnosis of lethal OI at wk 19 (11). The same overmodified collagen population as in cultured skin fibroblasts was identified in the patient's CVC, but it was noted that collagen produced by control CVC was more modified than that produced by dermal fibroblasts (11).

To circumvent the problem of collagen overmodification in AFC and CVC, we studied collagen synthesis in intact $\mathrm{CV}$ and found that 1 ) collagen deposited in CV can be extracted and analyzed directly, and 2) CVS synthesize collagens I, III, and V, which can be detected after short-term incubation with radioactive precursors. We next developed a protocol for the biochemical detection of structural defects of collagens I and III by short-term CVOC and applied it successfully to the study of 10 pregnancies at risk for lethal OI, EDS IV, and EDS VII, as well as to 11 control pregnancies not at known risk for collagen disorders.

\section{METHODS}

CVS from control pregnancies and from pregnancies at risk. During the initial phase of this study, the goal of which was to ascertain de novo collagen synthesis in CV and to establish the analytical protocol, control CVS were obtained with informed consent during voluntary pregnancy termination. Prenatal diagnosis was then offered to those families in whom previous biochemical examination of fibroblast cultures from the index case had shown an unambiguous anomaly of either collagen I or collagen III (Table 1). Diagnosis was performed with informed consent of the families, who understood that they were participating in an experimental study. Aliquots of one or two control CVS were usually studied in parallel. Two pregnancies at risk for EDS IV, one at risk for EDS VIIB, six at risk for OI, and 11 control pregnancies were biochemically monitored. For further details see Table 1.

CV sampling and preparation. CVS were dissected free from maternal material and hand-delivered or sent by express mail the same day in either MEM with $10 \%$ FCS or Chang medium. The samples reached our laboratory within $24 \mathrm{~h}$ after they had been taken, except for one instance in which the transport took $1 \mathrm{wk}$, without significant loss of biologic activity of the specimen as judged by the incorporation of radiolabeled amino acids.

Biochemical analysis of cell cultures. Dermal fibroblasts were cultured in MEM with $10 \%$ FCS (both from Gibco, Life Technologies, Basel, Switzerland) and grown under standard conditions (12). A total of 250000 cells per $35-\mathrm{mm}$ dish were seeded and after $24 \mathrm{~h}$ were metabolically labeled for an additional $16 \mathrm{~h}$ with $10 \mu \mathrm{Ci}$ each of $\left[{ }^{3} \mathrm{H}\right]$ proline and $\left[{ }^{3} \mathrm{H}\right] \mathrm{glycine}$ in the presence of $50 \mu \mathrm{g} / \mathrm{mL}$ ascorbate and $50 \mu \mathrm{g} / \mathrm{mL}$ catalase. Separate harvesting and pepsinization of collagen from culture medium and cell layer were as described (12). After SDS-gel electrophoresis $(5 \%$ acrylamide; acryl:bisacryl $=37.5: 1)$ in the presence of $0.5 \mathrm{M}$ urea, the radiolabeled collagens were detected by autoradiofluorography. Two-dimensional mapping of cyanogen bromide-cleavage peptides of collagen chains (cleavage time, $90 \mathrm{~min}$ ) was performed as described $(12,13)$. Control CVC and AFC were established from CVS and amniotic fluid, respectively, grown for $3 \mathrm{wk}$, and treated like dermal fibroblasts for analysis.

Biochemical analysis of CVOC. Briefly, upon delivery (d 1), the amount of each sample in mg was estimated by comparison with calibration photographs. CV (20-30 mg) were washed twice in MEM without additives and incubated overnight in a mixture of $500 \mu \mathrm{L}$ of MEM (plus antibiotics, $5 \mathrm{mM}$ glutamine, and $10 \%$ dialyzed FCS), 50 $\mu \mathrm{L}(50 \mu \mathrm{Ci})$ of ${ }^{3} \mathrm{H}[2]$ glycine, $50 \mu \mathrm{L}(50 \mu \mathrm{Ci})$ of ${ }^{3} \mathrm{H}[2,3]$ proline, and $50 \mu \mathrm{L}$ of L-ascorbate (freshly prepared at $1 \mathrm{mg} / \mathrm{mL}$ water, final concentration $75 \mu \mathrm{g} / \mathrm{mL}$ ) at $37^{\circ} \mathrm{C}$ and $5 \% \mathrm{CO}_{2}$. The incubation was performed with the tubes in an upright position and the caps loosened to allow gas exchange. On $\mathrm{d} 2$ the tubes were placed on ice and the villi were homogenized in their incubation me- 
Table 1. Biochemical collagen analysis in CVOC

\begin{tabular}{|c|c|c|c|c|c|c|}
\hline CVOC & wk & $\begin{array}{c}\text { Clinical data-collagen chemotype in } \\
\text { SDS-PAGE }\end{array}$ & $\begin{array}{l}\text { Molecular defect of affected } \\
\text { parent or index case }\end{array}$ & Recurrence risk & $\begin{array}{l}\text { Collagen } \\
\text { analysis }\end{array}$ & $\begin{array}{l}\text { Clinical } \\
\text { outcome }\end{array}$ \\
\hline PET-I & 11 & $\begin{array}{l}\text { 1st pregnancy of mother with EDS type } \\
\text { IV-additional faster migrating } \\
{[\alpha 1(\mathrm{III})] \text {-trimer }}\end{array}$ & $\begin{array}{l}\text { Gly545Cys in } C O L 3 A 1 \\
\text { (manuscript in preparation) }\end{array}$ & $50 \%$ & Normal & Healthy \\
\hline PET-II & 11 & 2nd pregnancy, see PET-I & Gly545Cys in COL $3 A 1$ & $50 \%$ & Normal & Healthy \\
\hline FRA & 10 & $\begin{array}{l}\text { Father with EDS VIIB-persistent } \\
\text { pNa } 2 \text { (l) revealed as } \alpha 2(\mathrm{l}) \text {-doublet }\end{array}$ & $\begin{array}{l}\text { Skipping of exon } 6 \text { in } C O L 1 A 2 \\
\text { (Ref. 1) }\end{array}$ & $50 \%$ & Normal & Healthy \\
\hline MED-I & 11 & $\begin{array}{l}\text { 3rd pregnancy } \\
\text { 1st child stillborn with deformed limbs } \\
\text { 2nd pregnancy terminated at wk } 17 \\
\text { because of OI-overmodified collagen I } \\
\text { produced by dermal fibroblasts of } \\
\text { aborted fetus }\end{array}$ & $\begin{array}{r}\text { Gly355Asp in COL1A1 } \\
\text { (as determined later) }\end{array}$ & $\begin{array}{l}\geq 5-8 \% \\
\text { Parental mosaicism? }\end{array}$ & Normal & Healthy \\
\hline MED-II & 11 & 4th pregnancy, see MED-I & $\begin{array}{r}\text { Gly355Asp in COL1A1 } \\
\text { (as determined later) }\end{array}$ & $\begin{array}{l}\geq 5-8 \% \\
\text { Maternal mosaicism } \\
\text { (as determined later) }\end{array}$ & Abnormal & Affected \\
\hline GSC-I & 11 & $\begin{array}{l}\text { 2nd pregnancy } \\
\text { previous child born with OI II- } \\
\text { formation of a } \alpha 1(1) \text {-dimers detected as } \\
\text { additional band }\end{array}$ & $\begin{array}{l}\text { Gly691Cys in COL1Al (Ref. } \\
\text { 21) }\end{array}$ & $5-8 \%$ & Normal & Healthy \\
\hline GSC-II & 11 & 3rd pregnancy, see GSC-I & Gly691Cys in COL $1 A 1$ & $5-8 \%$ & Normal & Healthy \\
\hline TIT & 10 & $\begin{array}{l}\text { 2nd pregnancy } \\
\text { Previous child diagnosed with OI at wk } \\
17 \text {-overmodified collagen I produced by } \\
\text { dermal fibroblasts of aborted fetus }\end{array}$ & Not determined & $5-8 \%$ & Normal & Healthy \\
\hline ERF & 11 & $\begin{array}{l}\text { 2nd pregnancy } \\
\text { 1st child died at birth from OI II-his } \\
\text { dermal fibroblasts produced } \\
\text { overmodified collagen I }\end{array}$ & Not determined & $5-8 \%$ & Normal & Healthy \\
\hline
\end{tabular}

dium with an ultrasonic cell disruptor using a microtip (Branson Ultrasonics Corp., Danbury, CT; five strokes, $50 \%$ pulse, setting 7). CV were then digested for $2 \mathrm{~h}$ at $20^{\circ} \mathrm{C}$ after addition of $65 \mu \mathrm{L}$ of a solution of porcine pepsin (Boehringer-Mannheim, Mannheim, Germany) dissolved in $1 \mathrm{~N} \mathrm{HCl}(1 \mathrm{mg} / \mathrm{mL})$. The digestion was stopped by addition of $65 \mu \mathrm{L}$ of $1 \mathrm{~N} \mathrm{NaOH}$, and the suspension cleared at $2000 \times g$ for $10 \mathrm{~min}$. The supernatant was transferred to a fresh tube, and proteins were precipitated by adding $1 / 2$ volume of absolute ethanol for $2 \mathrm{~h}$ at $-20^{\circ} \mathrm{C}$. The resulting pellets were dissolved in 130 $\mu \mathrm{L}$ of sample buffer (14) supplemented with $0.5 \mathrm{M}$ urea and boiled for $3 \mathrm{~min}$. Aliquots of 20 and $60 \mu \mathrm{L}$ per sample (equivalent to $5-8 \mathrm{mg}$ and $15-25 \mathrm{mg}$ of extracted $\mathrm{CV}$, respectively) were loaded onto SDS gels. The gels were stained overnight with Coomassie Blue R-250 and destained on $\mathrm{d} 3$ for $1 \mathrm{~h}$ for visualization of collagens deposited in vivo into the extracellular matrix (stroma). These results were documented photographically and the gels further processed for autoradiography (15) and exposed to Kodak X-AR films from d 4 to d 5 , at which time fluorograms were developed to visualize collagens synthesized de novo by $\mathrm{CV}$ in culture.

Case report: family MED (Table 1). In this nonconsanguineous Spanish couple and respective relatives (referred to as family MED), there is no significant medical history of fractures by inadequate trauma, joint hypermobility, scleral discoloration, bone deformities, hearing loss, or dental abnormalities. The mother measures 153 $\mathrm{cm}$ tall and is shorter by $12-22 \mathrm{~cm}$ than her female first-degree relatives. X-ray examination of her spine was unremarkable. The father is $177 \mathrm{~cm}$ tall, approximately as tall as his male first-degree relatives.

The couple's first pregnancy (mother aged $25 \mathrm{y}$, father aged $27 \mathrm{y}$ ) resulted in the birth of a stillborn fetus at the 32nd gestational wk (Spain, January 1990) who reportedly had short and malformed limbs and a deformed skull. No autopsy was done, and no $x$-ray information was available. During the second pregnancy, bony abnormalities were sonographically detected at wk 16 and confirmed at wk 17 and 18, suggesting the presence of a severe form of OI (Fig. 1, left column). Autopsy after pregnancy termination at wk 18 revealed a macerated male fetus (hereafter referred to as fetus II) without internal malformations but with deformities compatible with OI type II. Postmortem $\mathrm{x}$-rays showed an unossified skull, beaded ribs with multiple fractures, and severely bowed femora and humeri due to multiple old and fresh fractures (not shown). Collagen analysis by SDS-PAGE of cultured dermal fetal fibroblasts revealed a structural collagen I defect (Fig. 2) (see below).

Given the outcome of the first two pregnancies, additional pregnancies of this couple were considered to be at significant risk for recurrence of lethal OI because of the possibility of parental mosaicism for a collagen I mutation. At wk 10 of the third pregnancy, CV sampling was performed (karyotype was normal), and collagens were analyzed according to our protocol for CVOC (see 

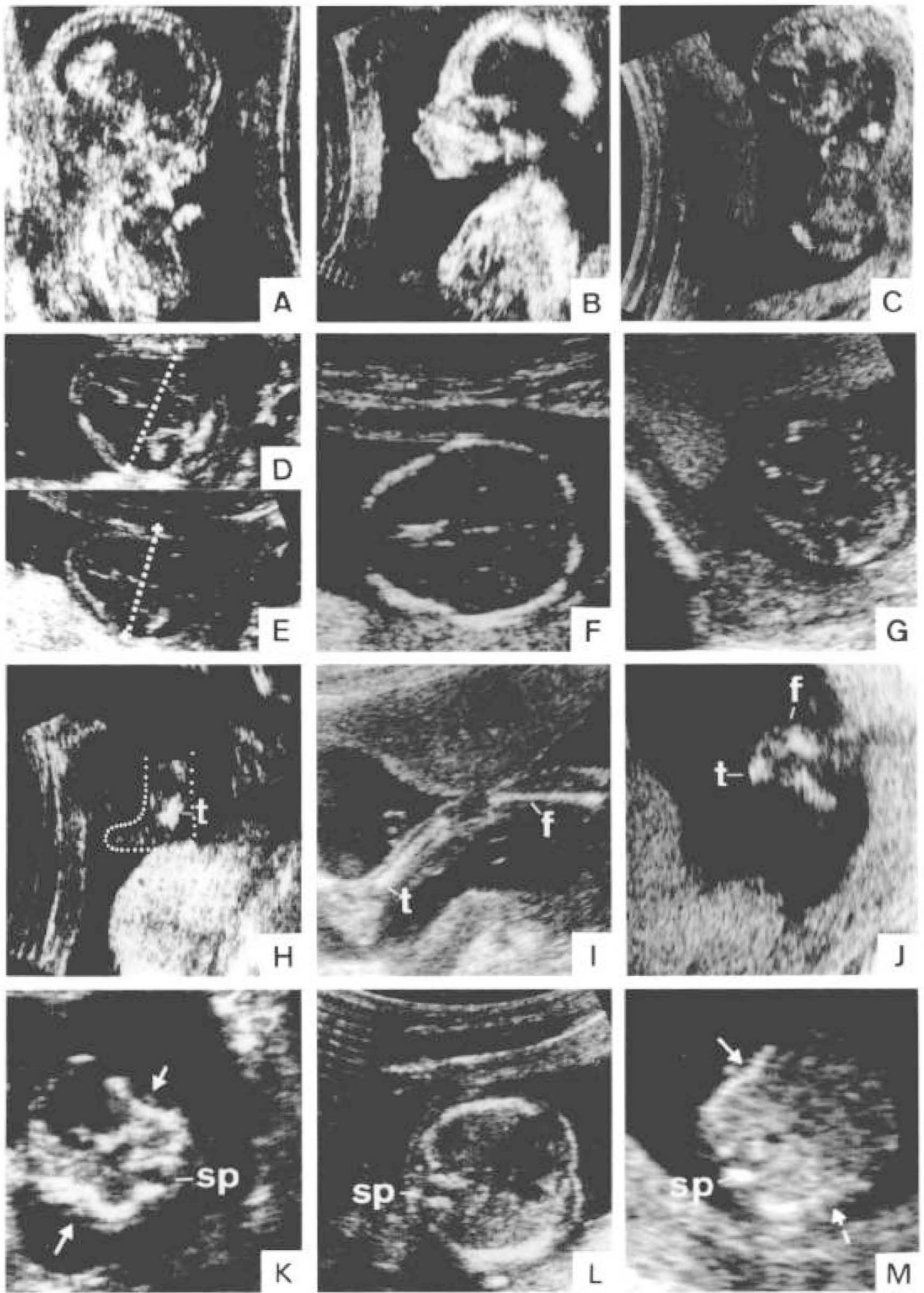

Figure 1. Ultrasonographic features of three consecutive pregnancies in family MED. Fetuses II and IV were affected with perinatally lethal OI type II: their poorly ossified skulls allowed resolution of intracerebral structures $(A, D, E, C$, and $G)$ and were soft and easily deformed by the pressure of the transducer $(E)$ in contrast to the unaffected fetus III $(B$ and $F)$. In both affected fetuses, the limbs were short and malformed. The lower limbs showed clumpy echogenic structures compatible with compressed and fractured bones of tibiae $(t)$ and femur $(f)(H$ and $J)$; compare them with the long and well-formed bones of the healthy fetus III $(I)$. On the transthoracic section, the rib cage shows a bilateral impression due to angulation of the ribs (arrows) in the affected fetuses II and IV ( $K$ and $M$, respectively) in contrast to the regular circle described by the rib cage of unaffected fetus III $(L)$. The spine is marked $s p$ for orientation. Different magnifications of the ultrasound images shown here do not reflect the real developmental size differences between the three fetuses. 


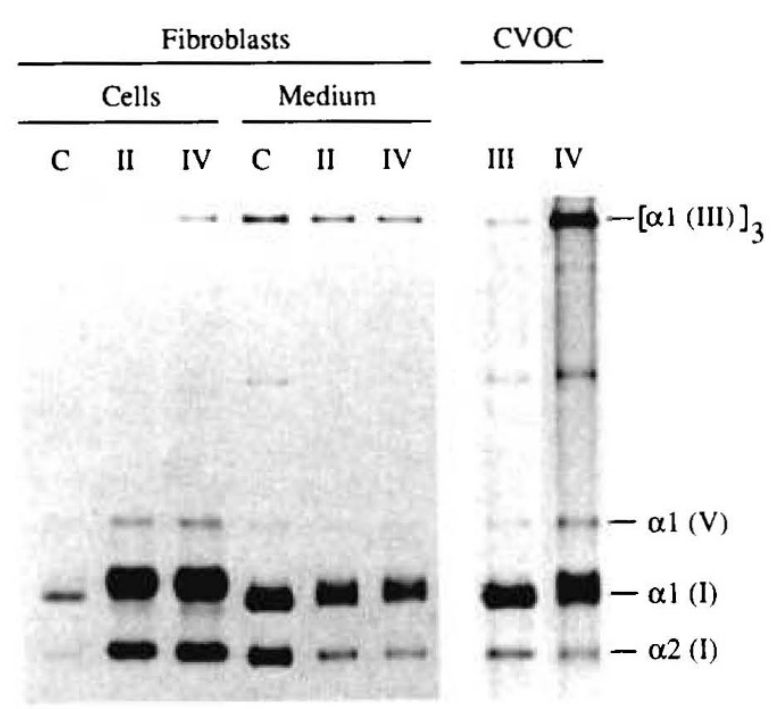

Figure 2. Collagen I analysis in fibroblasts and CVOC of healthy fetus III and fetus IV affected with OI in family MED. Left panel: Fluorogram of SDS-PAGE of pepsin-extracted collagen from cell layer and culture medium from skin fibroblasts of a control $(C)$ and fetuses II and IV. As initially identified in fibroblasts from the index case, fetus II, there was marked retention of collagen $\alpha(\mathrm{I})$-chains in the cell layer, reduced secretion into the culture medium, and reduced electrophoretic mobility of $\alpha 1(\mathrm{I})$ - and $\alpha 2(\mathrm{I})$-chains in both compartments. Right panel. Collagens extracted from CVOC from pregnancies III and IV in family MED. The bands represent de novo synthesized collagens. Typically, both samples showed an elevated $\alpha 1(I): \alpha 2$ (I) ratio compared with that in fibroblasts, whereas the characteristically reduced electrophoretic mobility was only detected in CVOC of pregnancy IV, which was confirmed in skin fibroblasts from the aborted fetus IV (left panel).

above). The results predicted an unaffected fetus III (Fig. 2), as did repeated ultrasound examinations (Fig. 1, middle column); a healthy girl, now $2 \mathrm{y}$ old, was born at term. The fourth pregnancy was characterized by normal ultrasound findings at wk 11, when CV sampling was performed. Karyotyping in fetus IV was normal $(46, X Y)$, whereas biochemical analysis revealed collagen I abnormalities similar to those detected in the index case, fetus II (Fig. 2) (see below). Bony abnormalities were evident on ultrasonography repeated at wk 14 (Fig. 1, right column). Postabortion studies were undertaken to ascertain the molecular basis of recurrent OI type II in family MED.

Molecular genetic studies in family MED. Total mRNA prepared from confluent fibroblast cultures by the guanidinium thiocyanate-cesium chloride method (16) was retrotranscribed to first-strand cDNA using a commercially available kit (Boehringer-Mannheim). Aliquots of cDNA were amplified by PCR using Taq polymerase (Promega, Madison, WI) and several oligonucleotide primer couples specific for the $\alpha 1$ (I)CB7, CB3, and CB8 regions of both $\alpha 1(\mathrm{I})$ - and $\alpha 2(\mathrm{I})$-chains in the presence of ${ }^{32} \mathrm{P}$-dATP (approximately $1 \mu \mathrm{Ci}$ in each $20-\mu \mathrm{L}$ reaction). For analysis of SSCP, the PCR products were diluted with formamide loading buffer (16), denatured by boiling, and electrophoresed at room temperature on $6 \%$ polyacrylamide gel with $8 \%$ glycerol in 0.5 Tris-borate-EDTA buffer at $8 \mathrm{~W}$ constant power; the dried gels were exposed to Kodak
XAR-1 film for autoradiography. PCR fragments that proved positive in the SSCP analysis were cloned into the TA cloning vector (Invitrogen, San Diego, CA) and sequenced using the Sequenase kit (U.S. Biochemicals, Cleveland, $\mathrm{OH}$ ) and ${ }^{32} \mathrm{P}$-dATP. After identification of a point mutation in the COL1A1 cDNA from the index case, fetus II, PCR amplification followed by restriction enzyme digestion (with $\mathrm{MboI}$ ) was used to demonstrate the presence or absence of the mutation in the fibroblast cDNA of both fetuses II and IV, DNA extracted from peripheral blood of both parents and healthy controls, and DNA extracted from buccal mucosal cells of the mother. Digested PCR fragments were electrophoresed in $4 \%$ NuSieve agarose (FMC Bioproducts, New York, $\mathrm{NY}$ )/ethidium bromide or in $10 \%$ polyacrylamide gels and visualized under UV light or by silver staining (SilverStain-Plus; BioRad, Hercules, CA), respectively.

\section{RESULTS}

Collagen synthesis in cultures of normal AFC and normal CVC grown for 3 wk. In accordance with earlier reports (9, 10 ), we found that AFC produced only type I collagen homotrimers, consisting of $\alpha 1$ (I)-chains that were highly overmodified (Fig. 3), whereas CVC were similar to fibroblast cultures in terms of the relative proportions of collagens I, III, and V and of posttranslational modification of collagen $\alpha$-chains (Fig. 3) (see below).

Collagen analysis in normal CVOC. After pepsin extraction of CVOC, collagens I, III, and V were detectable by SDS-PAGE and Coomassie Blue staining (demonstrating collagens already deposited in the extracellular matrix of $\mathrm{CV}$; not shown) as well as by autoradiofluorography (identifying collagens synthesized during short-term culture; Fig. 3). The CVOC incubation medium did not contain significant amounts of collagen (not shown); hence, CV were homogenized and processed together with their supernatant (equivalent to a combination of cell layer and culture medium). Coomassie Blue staining of the gels was performed on d 3 (not shown), and autoradiofluorograms were obtained on $\mathrm{d} 5$. We did not observe major discrepancies between the two visualization methods.

Comparison of collagens synthesized by cultured normal fibroblasts, CVC, and control CVOC. In collagen extracted from CVOC, the ratio of $\alpha 1$ (I)- to $\alpha 2(\mathrm{I})$-chains was consistently higher than $2: 1$, indicating the presence of $\alpha 1(\mathrm{I})$ homotrimers (Fig. 3). In addition, the ratio of collagen III to collagen I was higher in CVOC than in dermal fibroblasts. The $\alpha$-chains of all collagen types from CVOC migrated slightly faster than those from cultured fibroblasts and CVC, indicating a lower degree of posttranslational modification. Cells cultivated from the CVS and examined after 3 wk of culture synthesized collagens appearing similar to those from dermal fibroblasts with respect to relative amounts, modification, and chain composition (Fig. 3). Besides these differences, which might be attributed to the more physiologic conditions of an 


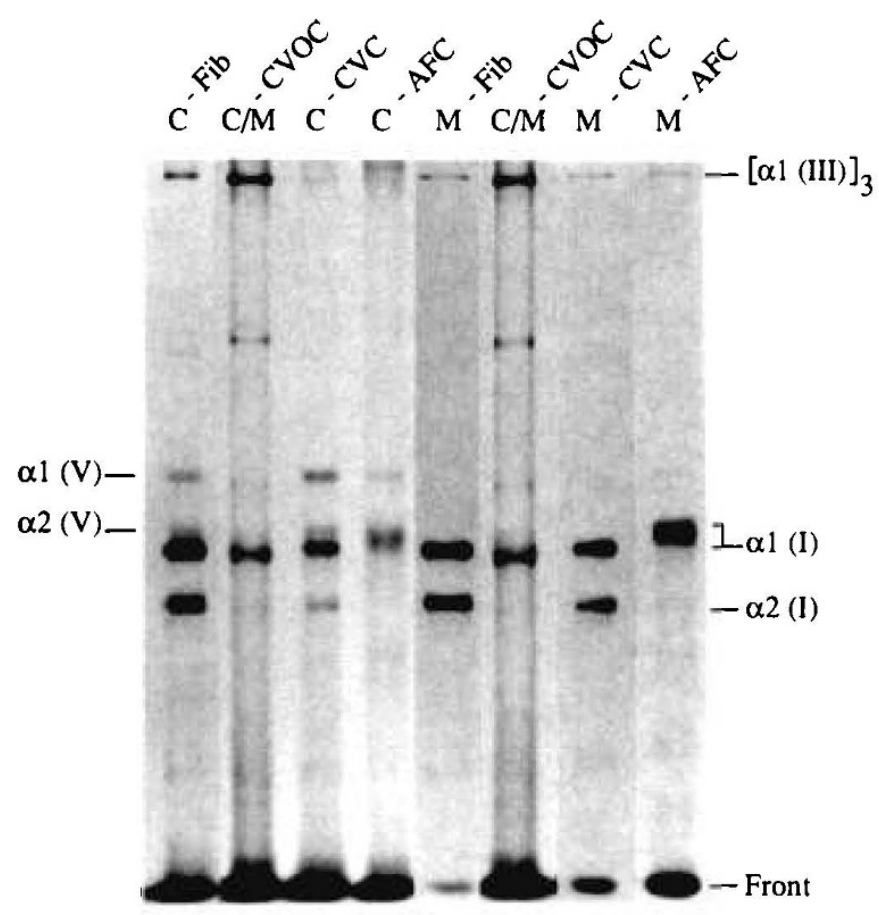

Figure 3. Comparison of radiolabeled collagen from normal dermal fibroblasts, normal CVC, and amniocytes with collagens extracted from CVOC. Fibroblasts (Fib) and CVC secreted similar amounts of pepsinstable collagens into the culture medium $(M)$. There was no difference in electrophoretic mobility of the respective $\alpha$-chains either in medium or cell layer $(C)$. The $\alpha$-chains from collagens I, III, and V extracted from tissue plus incubation medium $(C / M)$ from $C V O C$ migrate faster. The elevated ratio of $\alpha 1(\mathrm{I}): \alpha 2(\mathrm{I})$ indicates additional presence of $\alpha 1(\mathrm{I})$ homotrimers in this tissue. The ratio of collagen III:collagen I is increased to a variable degree in comparison with that in fibroblasts. In contrast, collagen I from AFC contains only $\alpha 1$ (I)-chains with markedly retarded electrophoretic mobility, whereas the $\alpha$-chains of collagens $V$ and III migrate normally.

organ culture as opposed to a cell culture, we did not observe any migration abnormalities of $\alpha$-chains from the 11 control CVOC. In all CVS, de novo collagen synthesis was sufficient to allow rapid autoradiographic detection of collagens I, III, and V and demonstrated collagens deposited in vivo.

Biochemical findings in CVOC of pregnancies at risk. In none of the five pregnancies at risk for OI type II were the characteristic electrophoretic abnormalities (Table 1) detected, and the fetuses were presumed to be unaffected by OI, with the reservation that our method was experimental. All pregnancies were subsequently monitored by ultrasound examinations. No abnormalities were detected, and healthy children were delivered in all instances. In CVS from the two pregnancies at risk for EDS IV, the additional collagen III band previously observed in fibroblasts cultured from the affected mother (unpublished manuscript) was not observed. Similarly, in the CVS from the pregnancy at risk for EDS VIIB, the characteristic pNo2(I)-doublet present in the affected father was absent (Table 1). Unaffected fetuses were predicted and no signs of EDS were present at birth or on follow-up examination of the three children.
Biochemical and ultrasonographic findings in family MED. Collagen analysis of fibroblasts established from the index case, fetus II, showed impaired secretion and increased retention of collagen I (Fig. 2), with retarded electrophoretic mobility of both $\alpha 1(\mathrm{I})$ - and $\alpha 2(\mathrm{I})$-chains. Two-dimensional cyanogen bromide-peptide mapping localized the focus of overmodification to the CB8 peptide of the $\alpha 1(\mathrm{I})$-collagen chain or the corresponding region of the $\alpha$ 2(I)-chain (Fig. 4, lane 2). Collagen analyzed from a CVS at wk 11 of the third pregnancy was normal (fetus III, Fig. 2), whereas analysis of CVS obtained at wk 11 of the fourth pregnancy revealed retarded migration of both $\alpha 1$ (I)- and $\alpha 2$ (I)-chains (fetus IV, Fig. 2). The electrophoretic pattern was similar to that previously obtained from skin fibroblasts of fetus II (Fig. 2).

In view of the biochemical findings, ultrasound was repeated at wk 14 (Fig. 1, right column) and revealed hypomineralization of the skull with enhanced visualization of cerebral structures. The head was soft and could be easily deformed by pressure of the ultrasonic transducer (compare with Fig. 1, left column) $(17,18)$. The deformed ribs showed bilateral angular impressions (Fig. 1 , right column). The right femur was bowed and shortened, and deformation and fractures of the left tibia and femur were visible (Fig. 1, right column). Radiographic examination of the aborted fetus IV confirmed hypomineralization of the skeleton and presence of thin, beaded ribs and bowed femurs (not shown).

Dermal fibroblast cultures established from fetus IV showed the same abnormal biochemical findings as in

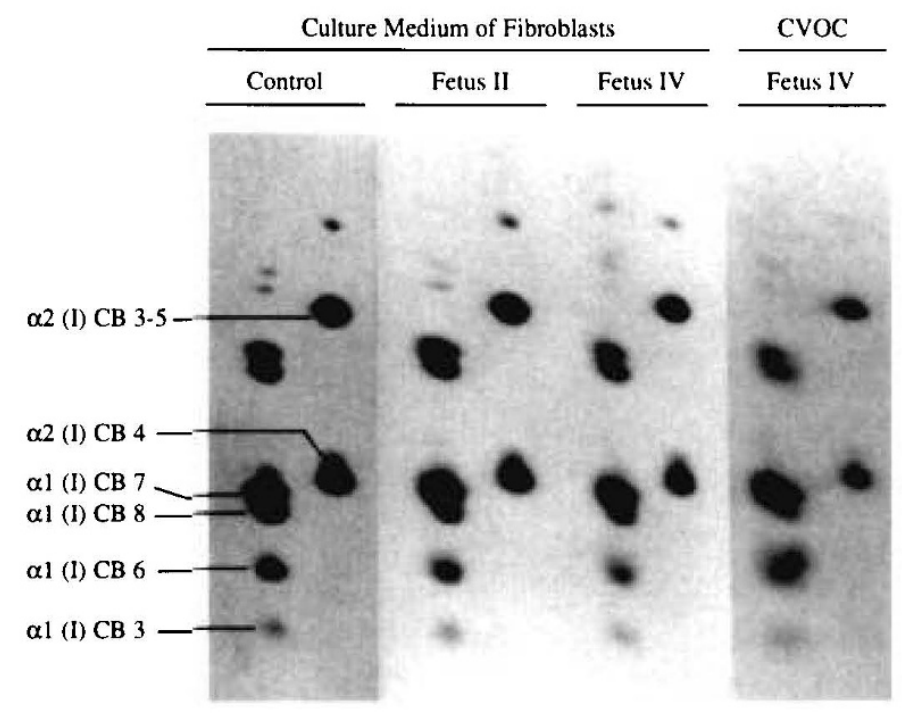

Figure 4. Two-dimensional mapping of cyanogen bromide-derived peptides from collagen I produced by cultured fibroblasts from a control and fetuses II and IV and by CVOC of fetus IV. Extracted collagens were run in the first dimension as described in Methods. The gel portions corresponding to the collagen $\alpha(\mathrm{I})$-chains were excised, and collagens were cleaved with cyanogen bromide and electrophoresed in the second dimension on a $10 \%$ gel. The peptides appear as round spots in the control, whereas in fibroblasts of fetuses II and IV and CVOC of fetus IV a similar pattern with slightly tilted CB7 and markedly tilted CB8 spots is evident. (Note: The rightmost lane had to be exposed for 4 mo due the small amount of material available.) 
fetus II (Fig. 2). Accordingly, two-dimensional analysis of both fibroblasts and CVOC from fetus IV revealed an abnormal peptide pattern similar to that detected in the index case, fetus II (Fig. 4, lanes 3 and 4).

Mutation identification in family MED. A PCR fragment encompassing codons 323 to 432 of pro- $\alpha 1(\mathrm{I})$-chains, amplified from fibroblast cDNA of fetus II, showed an abnormal migration pattern on SSCP analysis. Cloning and sequencing of this PCR product showed, in four of seven clones, a G-to-T transition at the second position of codon 355 , predicting the change from a glycine to an aspartic acid residue (Fig. 5). The sequence modification from GGTC to GATC created a new Mbol restriction site, the presence of which was used to confirm this mutation at the cDNA level in fetuses II and IV. Genomic DNA samples were then PCR-amplified using primers positioned in exon 23 and intron 23, incubated with MboI, and analyzed by electrophoresis (Fig. 6). Amplificates from control blood DNA and the father's blood DNA were not cleaved, amplificates from fibroblast DNA from fetuses II and IV were cleaved to yield bands of approximately equal amounts, and amplificates from mother's DNA were cleaved to an extent that was notably less than in both fetuses. The results are consistent with heterozygosity for an OI mutation in both fetuses and mosaic heterozygosity in the mother.

\section{DISCUSSION}

The biochemical search for collagen defects, previously limited to the study of dermal fibroblast cultures in the postnatal period, has become the method of choice for the diagnostic confirmation of OI and certain types of EDS in index patients because it is reliable, relatively rapid, and sensitive. Although a similar biochemical approach to prenatal diagnosis of OI and other collagen disorders would be desirable, early studies have shown that AFC synthesize homotrimeric collagen molecules with excessive posttranslational modification, making it

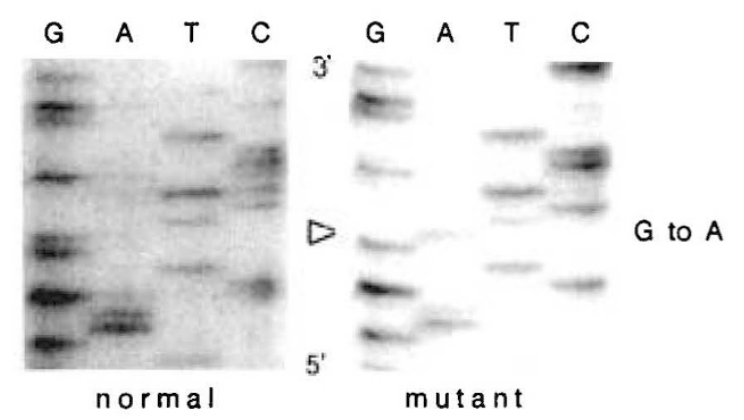

(GGT) Gly - 355 - Asp

(GAT)

Figure 5. DNA sequence analysis of normal and mutant $C O L 1 A 1$ cDNA clones from fetus II. The normal sequence is shown on the left. The mutant clone (right) contains a G-to-A transition (arrowhead) that converts codon 355 of the triple-helical domain from GGT (glycine) to GAT (aspartate). Note also that the mutation creates a restriction site for MboI (GATC) that is not present in the normal sequence and that was used to demonstrate the presence or absence of the mutation (Fig. 6).

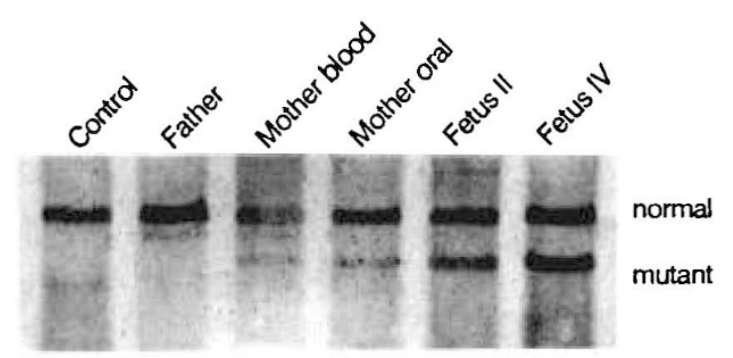

Figure 6. Mutation analysis in family MED by means of PCR amplification of genomic DNA and restriction digestion. Exon 23 of COL1A1 was amplified from genomic DNA, incubated with restriction endonuclease $\mathrm{MboI}$, separated by electrophoresis on a $10 \%$ acrylamide gel, and visualized by silver staining (see Methods). Neither blood DNA from a healthy control nor blood DNA from the father contained the mutant GATC sequence (Fig. 5) and therefore neither was cleaved by $\mathrm{Mbol}$ (only the upper, uncleaved band is visible). Approximately $50 \%$ of DNA from fibroblasts of both fetuses II and IV was cleaved (both upper and lower bands), indicating heterozygosity for the mutation. Only a fraction of DNA obtained from the mother was cleaved, indicating somatic mosaicism for normal cells and cells containing the mutation. There was no significant difference between DNA from blood and oral mucosa.

impossible to ascertain the presence of a structural defect $(9,10)$. Furthermore, CVC have been reported to produce heterotrimeric, albeit also overmodified, collagen (11). To circumvent this problem, we attempted prenatal diagnosis by direct biochemical analysis of isolated, whole CV. We have found that their extracellular matrix (stroma) contains significant amounts of collagen I and collagen III deposited in vivo and that they synthesize de novo sufficient amounts of collagen during metabolic labeling in short-term culture (CVOC) for analysis. These collagen populations can be extracted by pepsin digestion and visualized after SDS-PAGE. Although Coomassie blue staining of collagens formed in vivo was not as sensitive as autofluorographic identification of radioactive newly synthesized collagens, it provided preliminary information on the second day after receipt of samples and represented a safety step in case of metabolic failure of the biopsies (an event that we have not encountered so far).

We subsequently performed CVOC collagen analysis in a total of 21 pregnancies without encountering technical difficulties. Our preliminary studies showed that, in contrast to earlier findings (11), collagens synthesized by cultured CVC are similar to those produced by cultured fibroblasts. Cultured CVC therefore appear also to be suitable for prenatal collagen analysis, and they have been used for prenatal diagnosis of OI by other groups (19). However, because it takes several weeks to grow enough CVC for biochemical analysis, CVOC analysis is certainly preferable, because it provides final results by the fourth day after receipt of specimens and because it avoids the risk of maternal cell growth in cultured CVC.

CVOC analysis allowed us to correctly predict unaffected fetuses in seven pregnancies from five families at risk for EDS IV, EDS VII, and OI. In an additional family reported here, both an unaffected and an affected OI fetus were correctly predicted in consecutive pregnan- 
cies, and the underlying collagen I defect was determined. The responsible mutation is novel and adds to five other Gly $\rightarrow$ Asp substitutions in the $\alpha 1(\mathrm{I})$-chain, all of which have been lethal regardless of their position along the triple-helical domain (1). The mother was demonstrated to be mosaic for this mutation. Interestingly, although she had a readily detectable proportion of cells bearing this mutation in blood and oral mucosa, she showed no clinical features of $\mathrm{OI}$ aside from a shorter stature compared with her first-degree relatives. The findings emphasize the indication for prenatal diagnosis in families in which one offspring is affected by OI type II; birth of a second child with OI caused by a dominant collagen mutation should be regarded as highly suggestive for parental gonadal (if not somatic) mosaicism and implies a recurrence risk for future pregnancies possibly as high as $50 \%$.

Our prenatal biochemical diagnosis at wk 11 of severe OI was 3 wk ahead of its confirmation by ultrasonography around wk 14, which is currently the earliest time point for the diagnosis of skeletal abnormalities $(6,19,20)$. However, until more experience with CVOC is available, we suggest waiting for ultrasonographic confirmation by an alerted expert before pregnancy termination rather than acting on the basis of positive CVOC findings alone. Neither should CVOC analysis serve as a prenatal screening method; it is designed and suitable only for collagen I and III defects that have been previously biochemically characterized in each individual family, i.e. in an affected sibling or a parent. In such circumstances, collagen analysis by CVOC might become a rapid and reliable method for prenatal diagnosis.

Acknowledgments. The authors thank Drs. S. Savoldelli, F. Binkert, and G. Pescia (Institutes of Medical Genetics, Universities of Zürich and Lausanne) for their valuable assistance in obtaining and preparing chorionic villus samples. We are grateful to $\mathbf{N}$. Vogt and Gabi Weber for technical help and to Susanne Staubli and $L$. Burger for graphic and photographic work.

\section{REFERENCES}

1. Byers PH 1993 Osteogenesis imperfecta. In: Royce PM, Steinmann B (eds) Connective Tissue and Its Heritable Disorders: Molecular, Genetic and Medical Aspects. Wiley-Liss, New York, pp 317-350

2. Steinmann B, Royce PM, Superti-Furga A 1993 The Ehlers-Danlos syndrome. In: Royce PM, Steinmann B (eds) Connective Tissue and Its Heritable
Disorders: Molecular, Genetic and Medical Aspects. Wiley-Liss, New York, pp 351-407

3. Chu M-L, Prockop DJ 1993 Collagen: gene structure. In: Royce PM, Steinmann B (eds) Connective Tissue and Its Heritable Disorders: Molecular, Genetic and Medical Aspects. Wiley-Liss, New York, pp 149-165

4. Byers PH, Tsipouras, P, Bonadio JF, Starman BJ, Schwartz RC 1988 Perinatal lethal osteogenesis imperfecta (OI type II): a biochemically heterogenous disorder usually due to new mutations in the genes for type I collagen. Am J Hum Genet 42:237-248

5. Thompson EM, Young ID, Hall CM, Pembrey ME 1987 Recurrence risks and prognosis in severe sporadic osteogenesis imperfecta. J Med Genet 24:390-405

6. Ottavio D, Tamaro LF, Mandruzzato G 1993 Early prenatal ultrasonographic diagnosis of osteogenesis imperfecta: a case report. Am J Obstet Gynecol 169:384-385

7. Raghunath M, Bruckner P, Steinmann B 1994 Delayed triple helix formation of mutant collagen from patients with osteogenesis imperfecta. J Mol Biol 236:940-949

8. Shapiro JE, Phillips III JA, Byers PH, Sanders R, Holbrook KA, Levin SL, Dorst J, Barsh GS, Peterson KE, Goldstein P 1982 Prenatal diagnosis of lethal perinatal osteogenesis imperfecta (OI type II). J Pediatr 100:127-133

9. Crouch E, Bornstein P 1978 Collagen synthesis by human amniotic fluid cells in culture: characterization of a procollagen with three identical pro alpha-1(1) chains. Biochemistry 17:5499-5509

10. Byers PH, Wenstrup RJ, Bonadio JF, Starman B, Cohn DH 1987 Molecular basis of inherited disorders of collagen biosynthesis: implications for prenatal diagnosis. Curr Probl Dermatol 16:158-174

11. Grange DK, Lewis MB, Marini JC 1990 Analysis of cultured chorionic villi in a case of osteogenesis imperfecta type II: implications for prenatal diagnosis. Am J Med Genet 36:258-264

12. Steinmann B, Rao VH, Vogel A, Bruckner P, Gitzelmann R, Byers PH 1984 Cysteine in the triple-helical domain of one allelic product of the $\alpha 1$ (I) gene of type I collagen produces a lethal form of osteogenesis imperfecta. J Biol Chem 259:11129-11138

13. Barsh GS, Byers PH 1981 Reduced secretion of structurally abnormal type I procollagen in a form of osteogenesis imperfecta. Proc Natl Acad Sci USA 78:5142-5146

14. Laemmli, UK 1970 Cleavage of structural proteins during assembly of the head of bacteriophage T4. Nature 227:680-685

15. Laskey RA, Mills AD 1975 Quantitative film detection of ${ }^{3} \mathrm{H}$ and ${ }^{14} \mathrm{C}$ in polyacrylamide gels by fluorography. Eur J Biochem 56:335-341

16. Sambrook J, Fritsch EF, Maniatis T 1989 Molecular Cloning: A Laboratory Manual, 2nd Ed. Cold Spring Harbor Laboratory Press, Cold Spring Harbor, NY

17. Brons JTJ, van der Harten H, Wladimiroff JW, van Gejn HP, Dijkstra PF, Exalto N, Reuss A, Niermeijer MF, Meijer CJLM, Arts NFT 1988 Prenatal ultrasonographic diagnosis of osteogenesis imperfecta. Am J Obstet Gynecol 159:176-181

18. Pendola F, Filocamo M, Lituania M, Steinmann B, Superti-Furga A 1990 Radiological "metamorphosis" in a patient with severe congenital osteogenesis imperfecta. Eur J Pediatr 149:403-405

19. Dimaio MS, Barth R, Koprivnikar KE, Sussman BL, Copel JA, Mahoney MJ, Byers PH, Cohn DH 1993 First-trimester prenatal diagnosis of osteogenesis imperfecta type II by DNA analysis and sonography. Prenat Diag 13:589-596

20. Sharony R, Browne C, Lachman RS, Rimoin DL 1993 Prenatal diagnosis of the skeletal dysplasias. Am J Obstet Gynecol 169:668-675

21. Steinmann B, Westerhausen A, Constantinou CD, Superti-Furga A, Prockop DJ 1991 Substitution of cysteine for glycine- $\alpha 1-691$ in the pros 1 (I) chain of type I procollagen in a proband with lethal osteogenesis imperfecta destabilizes the triple helix at a site C-terminal to the substitution. Biochem J 279:747-752

22. Raghunath M. Steinmann B, DeLozier-Blanchet C, Extermann P, SupertiFurga A 1994 Direct biochemical analysis of collagens in chorion villus biopsies: prenatal diagnosis of recurrent lethal osteogenesis imperfecta caused by parental mosaicism for a COL1A1 mutation (abs). Eur J Pediatr 153:216 